\title{
Making the case for inclusive design
}

\author{
Sam Waller*, Mike Bradley, Ian Hosking, P. John Clarkson \\ University of Cambridge, Engineering Design Centre, United Kingdom
}

\section{A R T I C L E I N F O}

Article history:

Available online 26 March 2013

\begin{abstract}
A B S T R A C T
This paper describes the University of Cambridge, Engineering Design Centre's (EDC) case for inclusive design, based on 10 years of research, promotion and knowledge transfer. In summary, inclusive design applies an understanding of customer diversity to inform decisions throughout the development process, in order to better satisfy the needs of more people. Products that are more inclusive can reach a wider market, improve customer satisfaction and drive business success. The rapidly ageing population increases the importance of this approach. The case presented here has helped to convince BT, Nestlé and others to adopt an inclusive approach.
\end{abstract}

(c) 2013 Elsevier Ltd and The Ergonomics Society. All rights reserved.

\section{Introduction}

Every design decision has the potential to include or exclude customers. Inclusive design emphasises the contribution that understanding user diversity makes to informing these decisions. However, the complete set of success criteria for a business should include factors related to people, profit and planet (Elkington, 1998). Based on this framework, an example set of success criteria for a product is listed below:

\subsection{People}

- Utility is the extent to which the functionality of the product offers benefit to the user and society, and offers something better than other ways of doing it.

- Usability is the extent to which users can achieve goals with the product with effectiveness, efficiency and satisfaction, in realworld situations. In the context of inclusive design, the 'users' should encompass the range of human diversity across the population, in which case usability overlaps with accessibility.

- Desirability is the extent to which the product motivates purchase and ongoing usage, given the total cost of ownership.

\subsection{Profit}

- Commercial viability is the extent to which the product delivers a suitable return on investment over its life-cycle, while conforming to and enhancing the brand.

\footnotetext{
* Corresponding author.

E-mail address: sdw32@eng.cam.ac.uk (S. Waller).
}

- Technical viability is the extent to which the product can be manufactured and supported at the required production volume, with appropriate levels of reliability, robustness and customer support.

- Compatibility is the extent to which the product works together with other devices, and conforms to legal requirements and cultural expectations.

\subsection{Planet}

- Resource consumption is the extent to which the product encourages sustainable use of materials, water, human labour and land.

- Waste control is the extent to which the product enables and motivates control of outputs that may contaminate land, air or water.

- Energy efficiency is the extent to which the product minimises the energy that it uses across its life-cycle, while maximising the extent to which the product reduces the amount of energy that other things use.

Many of these characteristics are inter-related, and can be conflicting. For example, adding more features to increase the utility of the product will typically make the interface more complicated, which can compromise usability. Successfully managing and prioritising these conflicts is the key to delivering products that best satisfy the needs of the user, the business and the planet. Ignoring 'people' criteria can lead to products that do not sell at high volumes, or suffer from significant return rates. Ignoring 'profit' criteria can result in theoretical concepts that are never taken to market. Ignoring 'planet' criteria exposes the business to 
risks associated with substances becoming banned, plus rising energy and commodity prices.

This paper focuses on inclusive design for mainstream consumer products, which are produced at high volumes and sold in competitive markets. However, much of the content presented here-in is also applicable to the design of services and the built environment.

The remainder of this paper will focus on 'people' and 'profit' success criteria. However, the future ambition of the University of Cambridge, Designing Our Tomorrow initiative is to promote an integrated response to the challenges of ageing populations and sustainable use of the planet's resources. This initiative will integrate inclusive and sustainable design to holistically cover the complete framework of success factors presented earlier.

The University of Cambridge, Engineering Design Centre's (EDC) case for inclusive design is now presented, based on 10 years of research, promotion and knowledge transfer, as described in Clarkson and Coleman (2015). 'What is inclusive design?' is first considered in further detail, followed by 'Why design inclusively?' and 'How to design inclusively?'

\section{What is inclusive design?}

Delivering breakthrough advances across the success criteria requires a clear and communicated vision for what the product is about. Setting this strategy requires:

- Understanding diversity within the population.

- Responding to this diversity with informed design decisions.

\subsection{Understanding diversity}

Most of the commercial organisations that the EDC have worked with have started from a polarised viewpoint that 'mainstream' products are for 'fully able' users, and a separate, dedicated department supports the minority of customers with disabilities (Chamberlain et al., 2015). The case for inclusive design presented here-in was therefore developed to convince people who start from this viewpoint.

The United Nations (2006) Convention on the Rights of Persons with Disabilities defines disability based on being unable to participate in society on an equal basis with others. When determining a specific definition of disability, comparison with the majority is often used to define a threshold that determines when a person's impairment is severe enough for them to be classified as disabled. Defining such a threshold creates a split between the able-bodied and those with disabilities, which can be beneficial for people to gain recognition of their rights and to provide appropriate support.

However, in the context of product design, the 'disability' centric approach tends to encourage commercial organisations to develop specialist solutions to accommodate single types of severe ability loss, such as blindness or wheelchair use. Commercial organisations can easily overlook those with multiple minor ability losses, such as those that commonly occur with ageing, including agerelated long sightedness and arthritis. These minor ability losses may not be severe enough to meet a threshold definition for 'disability', but may cause significant difficulties when interacting with products.

Indeed, research commissioned by Microsoft (2003) to investigate the benefit of accessible technology makes the following comment:

“... the concept of 'disability' may have limited the understanding of the need for accessible technology. Instead of assuming that accessible technology is only useful to a distinct group of people with disabilities, the IT industry must consider the wide range of people who could benefit ..."

In order to better understand population diversity, the polarised separation of 'able-bodied' and 'disabled' is first challenged by introducing a segmented pyramid (Benktzon, 1993) to model the full range of ability variation within a population. The bottom segment of the 'Population Pyramid' represents those with no difficulties, and the severity of difficulties increases up the pyramid. Fig. 1 shows a specific interpretation of this pyramid model, where the prevalence data and definitions of difficulty levels are drawn from the Microsoft (2003) survey. An alternative breakdown of the 'Population Pyramid' is also presented within Clarkson et al., 2015.

Having framed ability variation as being continuous within the population, it is then important to consider co-occurring ability losses. Typical conceptions of disability focus on single types of severe ability loss, yet a detailed analysis (Waller et al., 2010) of the 1996/97 Disability Follow-up Survey (Grundy et al., 1999; Department of Social Security Social Research Branch, 2000) reveals that: "Of the people with some kind of severe ability loss, $83 \%$ of them also have another kind of ability loss".

Population diversity has been introduced first from the perspective of ability variation, but can be further broadened to consider diversity associated with different real-world contexts, lifestyle, aspirations, gender, and past experiences.

Eden et al. (2007) indicate that US women influence $80 \%$ of buying decisions, yet the results of a survey at the Consumer Electronics Show in 2006 indicate only 1\% of those surveyed believe that consumer electronics companies took women's needs into consideration.

Population diversity can further broadened to consider a diverse range of usage cases, such as when at home, at work, or on holiday, and a diverse range of environmental factors, such as ambient lighting, rain, cold weather, background noise, social pressure and fatigue (Elton and Nicolle, 2010). Other contextual factors such as looking after children may distract attention, and may limit the use of one or both hands. In summary, 'it's normal to be different, want different things, and do things differently' (Lange and Becerra, 2007; Hosking at al., 2010).

\subsection{Responding to diversity}

People of different ages, capabilities and social and cultural backgrounds have a diverse range of needs, desires and preferences.

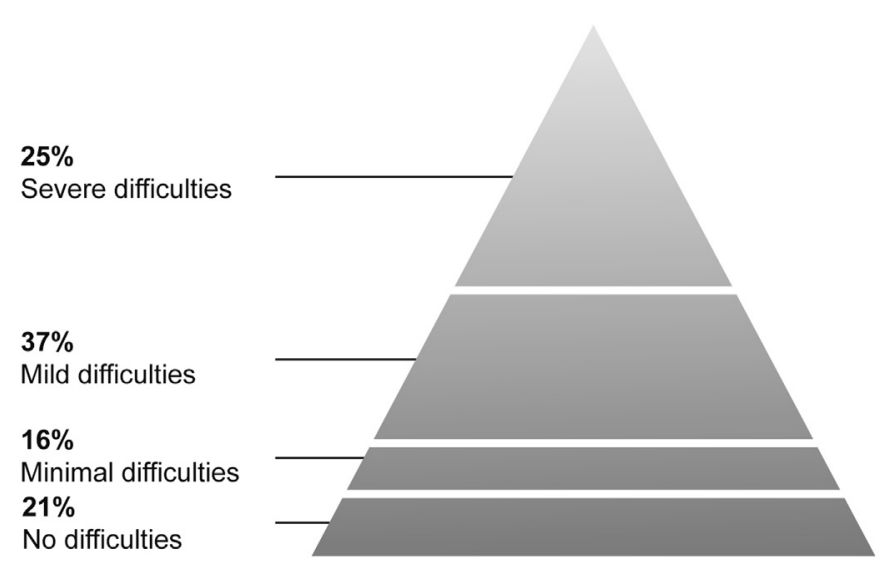

Fig. 1. A segmented 'Population Pyramid' showing a breakdown of vision, hearing cognitive, speech and dexterity difficulties for American adults of working age (16-64) from the Microsoft (2003) survey. Reproduced from Hosking et al. (2010), which also contains definitions of the different difficulty levels and further details of the survey. 
Inclusive design does not suggest that it is always possible (or appropriate) to design one product to address the needs of the entire population. Instead, inclusive design guides an appropriate design response to diversity in the population through:

- Developing a portfolio of products and derivatives to provide the best possible coverage of diversity within the 'Population Pyramid'.

- Ensuring that each individual product has clear and distinct target users.

- Making informed decisions to improve the success criteria for each product.

The strategy of targeting specific products to particular market segments is a commercially successful approach for satisfying conflicting user needs. Indeed, most of the organisations that the EDC has worked with were already using such a strategy. However, the entire segmentation approach tends to focus on the bottom of the 'Population Pyramid' (see Fig. 1), sometimes overlaid with specialist provision for those at the top of the pyramid. Existing segmentation models have tended to focus on the younger market, and segmentation of the older market is sometimes non-existent.

The pyramid model of diversity shown in Fig. 1 is extended in Fig. 2 to show how inclusive design aims to extend the target market further up the 'Population Pyramid', while accepting that specialist solutions may be required to satisfy the needs of those at the top of the pyramid. Such specialist solutions are often referred to as 'assistive technology', but the EDC avoids using this term because nearly all technology is assistive, and definitions of assistive technology are embedded within a disability-centric approach. Reducing the level of ability required to use a product can improve the user experience for a broad range of customers, in a variety of situations (Clarkson et al., 2011).

To summarise, inclusive design applies an understanding of customer diversity to the design of mainstream products, in order to better satisfy the needs of more people and deliver commercial success.

\subsection{Comparisons with design for all and universal design}

'Design for all' and 'Universal design' philosophies both have the same literal meaning. These philosophies originated from design of the built environment and websites, and were initially applied in the context of government provision (Design for All Foundation, 2003; Klironomos et al., 2005; Preiser and Ostroff, 2001). Inclusive design is about choosing an appropriate target population for a

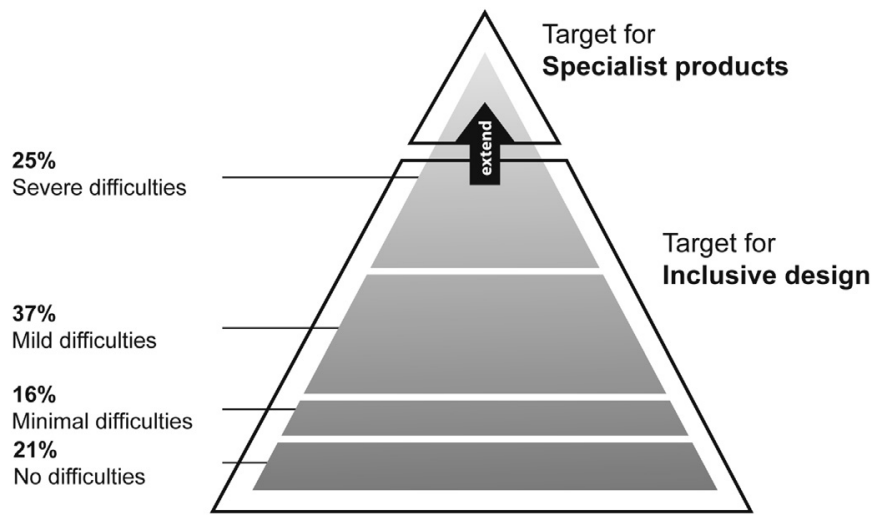

Fig. 2. Inclusive design is defined using the 'Population Pyramid' from Fig. 1 to represent an appropriate design response to diversity. Reproduced from Hosking et al. (2010). particular design, and making informed decisions to maximise the success criteria for the target market. For websites and the built environment, the target population is the whole population, in which case all three approaches have an equivalent meaning.

However, in the context of product design, both 'Design for all' and 'Universal design' approaches pragmatically accept that it is not always possible for one product to meet the needs of the entire population. This introduces an inherent contradiction in trying to work out what a 'Design for all' product really means. Nevertheless, these approaches maintain that all mainstream products should be accessible to as many people as technically possible (Preiser and Ostroff, 2001).

In contrast, inclusive design originated with product design. The EDC's case for inclusive design focuses more on informing decisionmaking in the context of people, profit, and planet success criteria, and planning a segmented design response to diversity within the 'Population Pyramid'. The 'Inclusive Design Research Centre's' page on 'What is inclusive design?' (OCAD University, 2012) also discusses similarities and differences between inclusive and universal design.

\subsection{Case studies}

One of the most compelling examples of inclusive design delivering business success is the BT Freestyle phone (Chamberlain et al., 2015; Warburton et al., 2015). Other good examples can be found within automotive industry: the 1999 Ford Focus was developed "to appeal to a greater number of buyers and their different lifestyles ... from the 5th percentile female to the 99th percentile male" (Malcolm, 1998). The heater controls for this car are shown in Fig. 3, which demonstrates one particular example of its inclusive design. The centre knob for the distribution control is larger than the knobs either side of it, which helps the driver distinguish between the controls without taking the eyes off the road. Furthermore, the larger diameter provides sufficient space for larger heater control graphics and reduces the effort of turning the knob.

Furthermore, with only 400 produced and a retail price of $\$ 670,000$, the Ferrari Enzo (see Fig. 4 ) is probably the last place one would expect to find inclusive design. A press article by Benoit et al. (2004) explains how Ferrari's design strategy for better access and egress helped the company improve the car's inclusivity:

"Climb into the latest Ferrari sports car and you are unlikely to notice the modifications designed with overweight, arthritic pensioners in mind ... the Italian carmaker is just one of many companies grappling with a demographic shift that challenges the fundamental rules of marketing and design ... the average buyer of a Ferrari road car is nearing 50 and set to get older ... Car designers are responding by [sparing the knees] with changes to the door height. The trick is that no one must be able

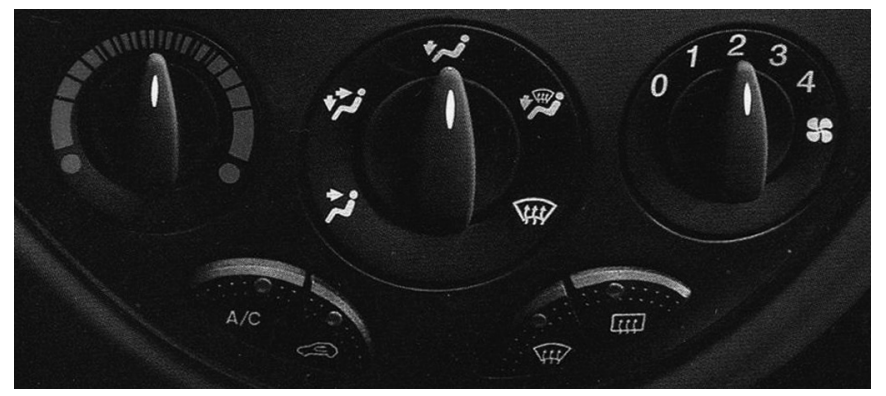

Fig. 3. Heating controls for the 1999 Ford Focus, where the centre knob for distribution control is larger than the knobs either side of it. Image source: Malcolm (1998). 


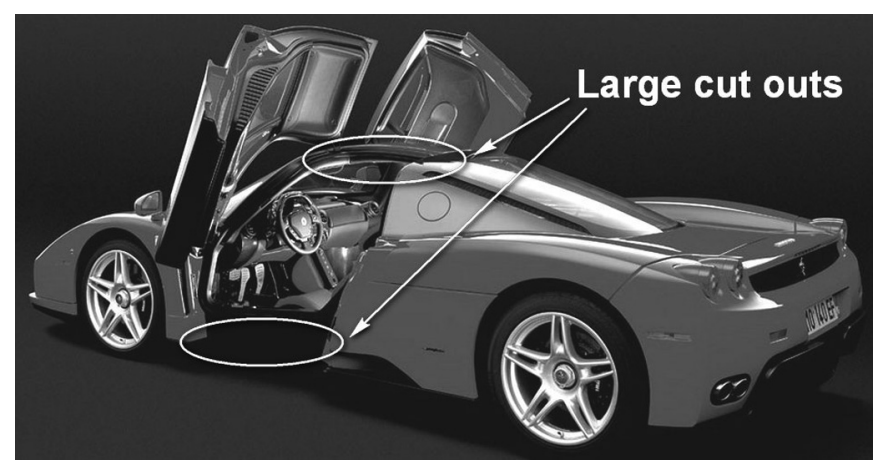

Fig. 4. Access to the Ferrari Enzo is improved by a unique door design, with large cutouts in the top and bottom of the chassis. Image source: www.carautoportal.com.

to tell ... 'The profile of our customers means we have to pay attention to practicality and functionality without compromising the sportiness,' says Giuseppe Bonollo, strategic marketing director. 'There are some engineering choices you can make which give you better accessibility and internal roominess. The way the doors open on the Ferrari Enzo, for example, allows part of the roof and part of the door undermoulding to come away as well, making it easier to enter the car.' The improved comfort of a modern Ferrari means the average distance driven by its owner has doubled from 2500 miles a year in 1990 to 5000 miles today."

\section{Why design inclusively?}

Having introduced and defined inclusive design, this section contains the business case. The key messages are:

- Ageing populations lead to growing opportunities for inclusive products.

- Inclusive design mitigates business risk.

- Simplicity can offer competitive advantage.

\subsection{Ageing populations}

In 2008, half the UK adult population were aged over 44 (Wright, 2010). Fig. 5 shows projected population changes compared to 2008 , indicating that all age groups over 45 represent emerging segments.

The over 50s spent GBP 276 billion in 2008, making up around $44 \%$ of the total family spending in the UK (Age UK, 2010). In the US, the over 50's annual income after tax is estimated at USD 2.4 trillion, which accounts for $42 \%$ of all after-tax income (Immersion, 2011).

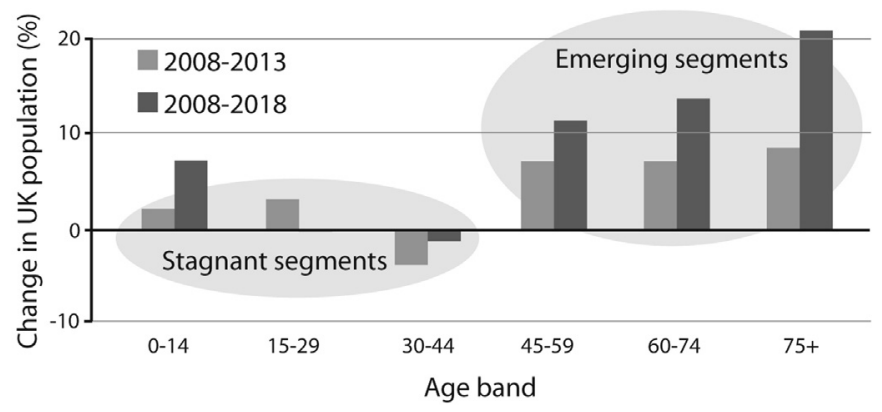

Fig. 5. Projected change in UK population by age band, calculated from Wright (2010).
Ageing is one of the key drivers of ability variation (Baltes and Lindenberger, 1997). Previous generations seemingly accepted that difficulties with products were expected with ageing. However, the baby-boomer generation now approaching retirement are less likely to tolerate products that they find difficult to use, especially as technology products are increasingly involved in accessing essential services: "For boomers, technology is contagious. And they don't consider themselves technology dunces. Instead, they blame manufacturers for excessive complexity and poor instructions" (Rogers, 2009).

\subsection{Mitigating risk}

Good design can happen by accident, but understanding user diversity as part of a rigorous inclusive design process mitigates business risk and ensures repeatable design success. It also mitigates the risk of undesirable and costly problems later in the product development lifecycle, such as:

- Excessive customer support costs.

- A large proportion of no-fault found warranty returns.

- Disability rights lawsuits.

- Costly rectification work required close to, or after launch.

- Customer dissatisfaction and brand degradation.

A report from the Design Council (Mynott et al., 1994) found that changes after release cost 10,000 times more than changes made during conceptual design. One costly example of insufficient accommodation of user diversity relates to a court ruling that the US Treasury discriminated against the blind and visually impaired by printing all denominations of currency in the same size and texture. Following this ruling, in 2011 the Treasury approved adding tactile features to US notes (Money Factory, 2011) at an estimated cost of $\$ 6.6$ billion (ARINC, 2009).

\subsection{Competitive advantage through simplicity}

Advancing technologies and digital interfaces mean that products can now offer more features at relatively low incremental cost. Indeed, companies can easily fall into the trap of competing in the 'feature race', trying to provide ever more features to keep one step ahead of the competition. However, increasing the number of features often hinders the usability of a device, due to the consequent increase in interface complexity and the reduction in size of controls, symbols and text.

The Philips Index (2010) found that the majority of Americans (63\%) think technology companies do not understand their needs when introducing new products. Indeed, 39\% of Americans think these companies 'fall in love with their own technologies'. The impact of excessive complexity is evident from Microsoft research, which asked users what they would like in the next version of Office: nine out of ten people asked for something already in the product (Capossella, 2005). Other companies have delivered business success through a focus on simplicity. The third of Google's ten design principles is 'simplicity is powerful' (Google, 2010). In particular, the company claims that:

"Google doesn't set out to create feature-rich products; our best designs include only the features that people need to accomplish their goals ... Google teams think twice before sacrificing simplicity in pursuit of a less important feature".

In the context of product design, making things simple is a challenging task. It requires a clear and distinct vision of who the product it is targeted at, and what functionality these users need. 
These targets should stimulate product innovation, leading to competitive advantage.

To summarise, products that are more inclusive can reach a wider market, improve customer satisfaction and drive business success, especially given the ageing population.

\section{How to design inclusively}

Having described inclusive design and presented its benefits, the next challenge is to answer the question: "what do I actually do?'. Inclusive design should be embedded in decisions made throughout the development process. In particular, successful inclusive design requires informed decision-making at the concept stage, because it can become prohibitively expensive to make changes later on. The process of concept generation is summarised here according to the core activities of exploration, creativity, evaluation and project management. These core activities answer four fundamental questions of concept design, shown in Fig. 6:

- What are the needs?

- How can the needs be met?

- How well are the needs met?

- What should we do next?

Fig. 6 synthesises many design models, such as those found in Cross (2000), and ties the fundamental questions of design together with the types of design activities that answer them.

These design activities need to determine both what the problem is, and what the solution is. Breaking this 'chicken and egg' deadlock requires a flexible approach, where successive cycles of exploration, creativity and evaluation should result in improved understanding of the real user and business needs, better solutions to meet the needs, and stronger evidence that the solutions meet the needs.

Activities associated with exploration, creativity and evaluation are generally applicable to problem-solving, as are successive improvement cycles. These activities are readily identifiable in other design models, including the Waterfall, Double Diamond, V and Spiral models (Clarkson and Eckert, 2005; Design Council, 2007). Although compatible with these other models, Fig. 6 is

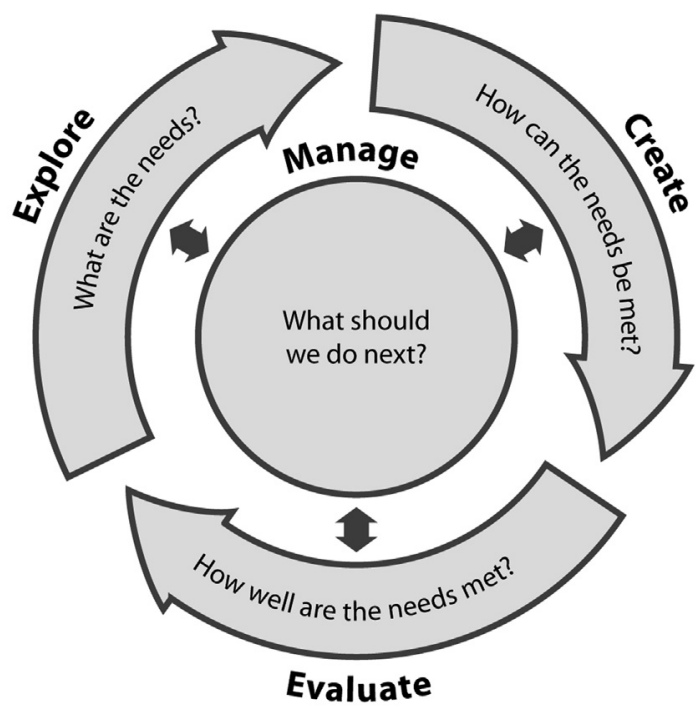

Fig. 6. Four fundamental questions of design are solved through successive cycles of exploration, creation and evaluation, guided by project management. Reproduced from Clarkson et al. (2011) more specifically focused towards concept design, and gives enhanced prominence to rapid iteration and early-stage evaluation. Furthermore, although exploration, creativity and evaluation are generic design activities, the specific emphases for inclusive design are:

- Understanding the true diversity of user and business needs.

- Applying this knowledge to better inform the design decisions taken throughout the development process.

- Evaluating rough prototypes with real users, before all the important decisions are finalised.

Fig. 6 showed the four fundamental questions of concept design, and the 'Design Wheel' in Fig. 7 shows the specific activities that answer these questions. Further detail is now provided on some of the particularly critical activities, namely 'observe users', 'generate personas', 'test with experts', 'test with users' and 'estimate exclusion'. The full set of activities are described in more detail in the 2nd edition of the Inclusive Design Toolkit (Clarkson et al., 2011).

\subsection{Observe users}

User observation is about uncovering what people really need, and what they really do. Observing actual behaviour is vital because participants may:

- Have a poor awareness of their own behaviour.

- Struggle to articulate their real needs.

- Find it difficult to imagine what is possible.

- Say what they think the interviewer wants to hear.

Focusing on observed user needs helps the design team to avoid overloading the product with every feature that they want, or think the users want. Although there are many specific techniques for observing users, contextual enquiry (Beyer and Holtzblatt, 1998) is particularly recommended because it complements observations of real-world behaviour with opinions elicited by interview.

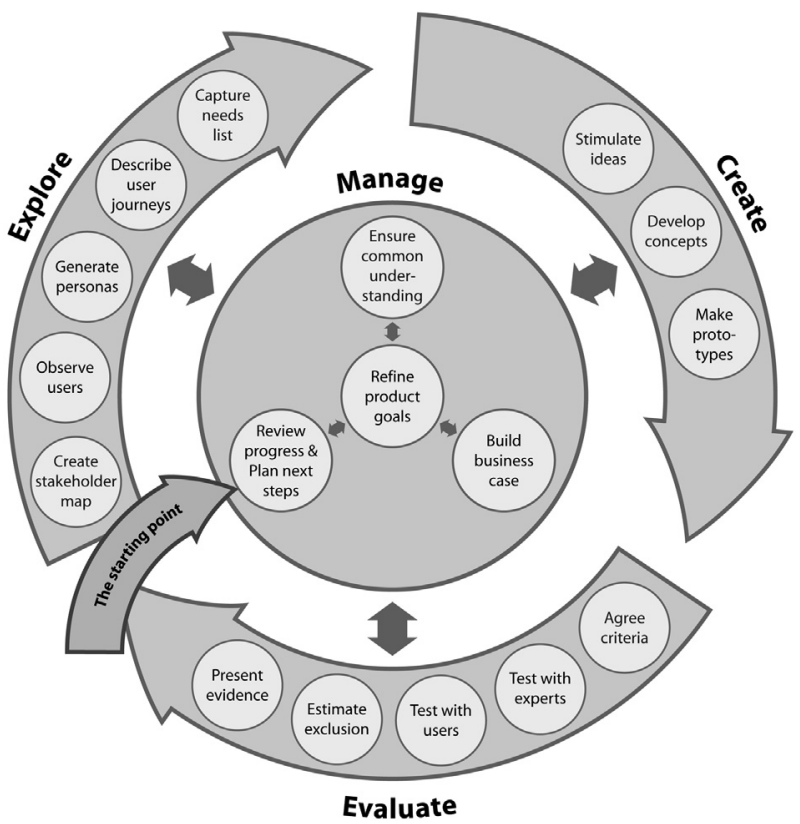

Fig. 7. The 'Design Wheel' shows the specific activities that help to answer the four fundamental questions of concept design. Reproduced from Clarkson et al. (2011). 


\subsection{Generate personas}

Personas (Pruitt and Adlin, 2006) are character descriptions of key users, usually accompanied with a photograph. The purposes of persona descriptions are to:

- Provide a method of summarising user diversity, which also includes physical, social and cultural contextual factors.

- Enable the project team to simulate standing in the shoes of their users.

- Focus the design team towards resolving real user needs, rather than trying to add in as many features as possible.

- Assist the evaluation of concepts and ideas.

Persona descriptions should be representative of larger groups of users, as discovered through observing users. Personas are particularly relevant to the business if they are created to represent different market segments. BT have successfully used this approach, but public domain examples of market segmentations are rare, because they are commercially sensitive.

\subsection{Test with experts}

Testing with experts is about systematically evaluating concepts against the agreed success criteria. For concept design, the judgement of a multidisciplinary team is required in order to quickly predict the relative performance potential of several initial concepts, across a wide range of success criteria.

Furthermore, impairment simulation can assist expert appraisals, providing an interactive and empathic way to:

- Understand how ability loss affects real world tasks, and specific conditions.

- Experience the frustration and difficulty that may be associated with capability loss.

- Evaluate alternative products or solutions with simulated ability loss.

- Communicate the impact of ability loss to others.

The low cost, speed and ease of access means that impairment simulators can be used both early on and repeatedly throughout the design process. However, impairment simulators should not be solely relied upon to draw conclusions about capability losses and their effects on product use, because no simulation can replicate living with capability reduction on an everyday basis.

Impairment simulators may be wearable, or software-based. Fig. 8 shows wearable simulation gloves and glasses that are available for sale through the Inclusive Design Toolkit website (Clarkson et al., 2011). This website also contains a freely available software-based impairment simulator for simulating different levels of severity within vision and hearing capabilities.

\subsection{Test with users}

Testing with users should objectively evaluate how effectively they can perform a particular goal (effectiveness), how quickly they can perform it (efficiency) and how much they like the experience (satisfaction) (ISO 9241-11, 1998). Early user testing is vital because it typically uncovers incorrect assumptions that were made by the design team, often unconsciously. These problems are usually trivial to fix, provided the testing is done before it is too late to change anything.

The types of users who are recruited should be carefully considered. If the users who are recruited are highly skilled, they will probably have no problems. However, if all the users are

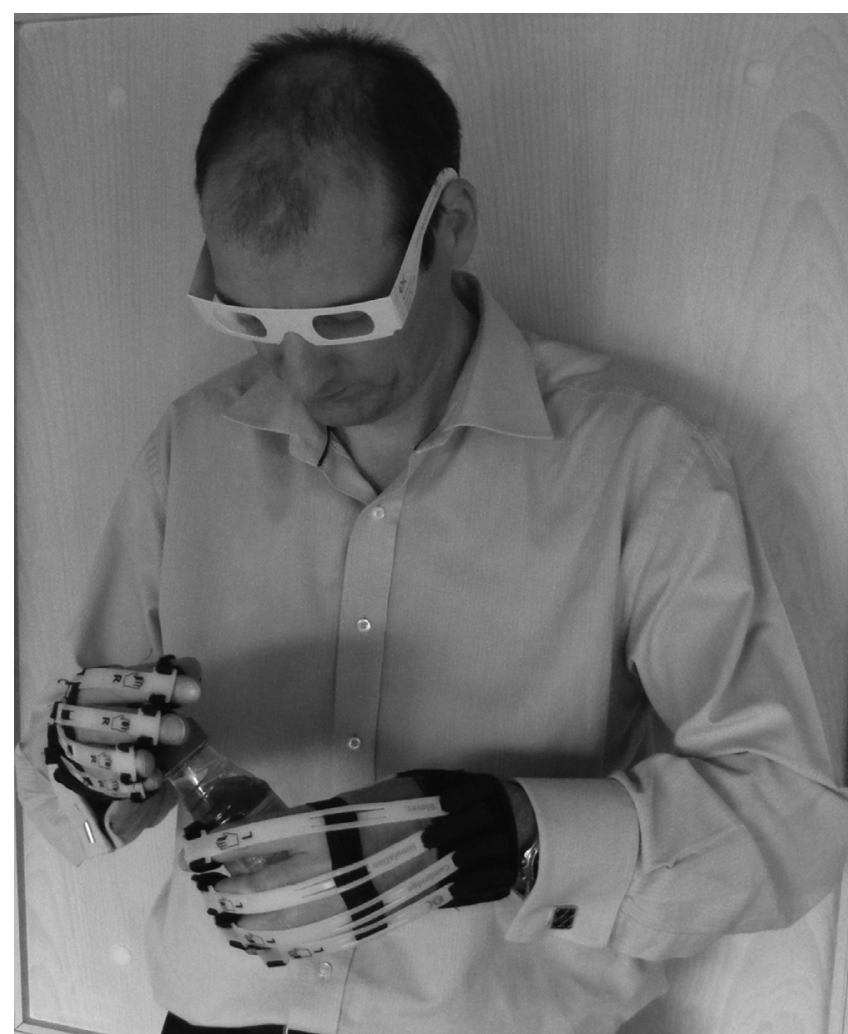

Fig. 8. The Cambridge Simulation Gloves and Cambridge Simulation Glasses are available for sale through the Inclusive Design Toolkit website (Clarkson et al., 2011).

minimally able, they may fail all the tasks. When performing trials with a small number of users, it is therefore recommended to intentionally select 'boundary users' who are on the limit of being able to use the product (Clarkson and Keates, 2003).

However, recruiting a few additional users with severe capability loss can inspire creativity that produces better mainstream designs (Cassim and Dong, 2015). Indeed predictive text was initially developed for those with dexterity impairment, yet subsequently became extremely popular on mobile phones (Newell, 2003; Arnott and Javed, 1990).

\subsection{Estimate exclusion}

Estimating exclusion identifies the task steps where a product or prototype places the highest demands on the following user capabilities:

- Vision

- Hearing

- Thinking

- Reach and Dexterity

- Mobility.

The process of estimating exclusion highlights the causes of frustration and exclusion, and prioritises these on a population basis. An exclusion calculator is freely available on the Inclusive Design Toolkit website (Clarkson et al., 2011).

\subsection{Implementing this process}

The activities described in Fig. 7 should be integrated into the early stages of an existing development process. They represent a 
basic set that should be considered the minimum required to design inclusively. Completing these activities delivers a lead concept, complete with evidence of its potential to satisfy the user and business needs. Subsequent design activities will be required to take this concept to market, but these are not covered here.

The 2nd edition of the inclusive design toolkit (Clarkson et al., 2011) contains a 'Design Process Checklist', which helps an organisation incorporate the 'Design Wheel' (shown in Fig. 7) into their existing development process. Furthermore, an 'Integrated Design Log' is provided to support each of the activities within the wheel.

\section{Conclusion}

Based on over 10 years of inclusive design research, promotion and knowledge transfer the EDC has developed a case for inclusive design.

Inclusive design is about developing a portfolio of products and derivatives to provide the best possible coverage of diversity within the 'Population Pyramid' (Fig. 2). Every design decision has the potential to include or exclude customers. Getting it right at the concept stage is critical: this requires early-stage user involvement and successive improvement cycles. The 'Design Wheel' (Fig. 7) shows this process model, together with the specific activities that need to be performed.

Products that are more inclusive can reach a wider market, improve customer satisfaction and drive business success, especially given the ageing population.

The case presented here was successful in convincing businesses within the Inclusive Design Consortium (Centre for Business Innovation, 2010) to adopt inclusive design processes and tools. New, more inclusive products will be coming to market as a direct result (Nestlé, 2012).

\section{References}

Age UK, 2010. The 'Grey Pound' Set to Hit £100bn Mark, Says Age Concern and Help the Aged. Press Release 20 January 2010.

ARINC, 2009. Study to Address Options for Enabling the Blind and Visually Impaired Community to Denominate US Currency. Prepared for Department of the Treasury, Bureau of Engraving and Printing. PDF Report available at: www.moneyfactory.gov (accessed October 2011).

Arnott, J.L., Javed, M.Y., 1990. Small text corpora in character disambiguation for reduced typing keyboards. In: Proceedings of RESNA 13. Washington, DC.

Baltes, Lindenberger, 1997. Emergence of a powerful connection between cognitive functions across the adult life span: a new window to the study of cognitiveaging? Psychology and Aging 12 (1), 12-21.

Benktzon, M., 1993. Designing for our future selves: the Swedish experience. Applied Ergonomics 24 (1), 19-27.

Benoit, B., Hall, B., Roberts, D., 2004. Ferrari's Greatest Design Challenge. Press article. Appeared in Financial Times, 20 Jan. 2004. Also available from: www.ferrariownersclub.co.uk (accessed October 2011).

Beyer, H., Holtzblatt, K., 1998. Contextual Design. Morgan Kaufmann Publishers.

Capossella, C., 2005. Key Note Address at Microsoft Professional Developers Conference 2005 (13 September 2005, Part of Bill Gates keynote address). www.microsoft.com/presspass/exec/billg/speeches/2005/09-13PDC05. aspx (accessed July 2010).

Cassim, J., Dong, H., 2015. Interdisciplinary engagement with inclusive design - the challenge Workshops model. Applied Ergonomics 46, 292-296.

Centre for Business Innovation, 2010. ID-1 Inclusive Design Consortium. Details available at: www.cfbi.com (accessed October 2011).

Chamberlain, M., Esquivel, J., Miller, F., Patmore, J., 2015. BT's adoption of customer centric design. Applied Ergonomics 46, 279-283.

Clarkson, P.J., Coleman, R., 2015. History of inclusive design in the UK. Applied Ergonomics 46, 235-247.

Clarkson, P.J., Eckert, C., 2005. Design Process Improvement: a Review of Current Practice. Springer, London, UK, ISBN 185233701X
Clarkson, P.J., Keates, S., 2003. Investigating the inclusivity of digital television settop box receivers. In: Digital Television for All. DTI, London. Appendix E. PDF Available at: www.digitaltelevision.gov.uk (accessed October 2011).

Clarkson, P.J., Coleman, R., Hosking, I., Waller, S.D., 2011. Inclusive Design Toolkit, second ed.. Available at: www.inclusivedesigntoolkit.com (accessed October 2012).

Clarkson, P.J., Waller, S.D., Cardoso, C., 2015. Approaches to estimating user exclusion. Applied Ergonomics 46, 304-310.

Cross, N., 2000. Engineering Design Methods: Strategies for Product Design, third ed. John Wiley \& Sons, Chichester, UK., ISBN 0471872504

Department of Social Security Social Research Branch, 2000. Disability Follow-up to the 1996/97 Family Resources Survey [computer File]. UK Data Archive [distributor], Colchester, Essex. SN: 4090. The complete set of questions are avail. at: http://www.esds.ac.uk/doc/4090/mrdoc/pdf/4090userguide.pdf (accessed October 2011).

Design Council, 2007. 11 lessons: Managing Design in 11 Global Companies. PDF avail. at. www.designcouncil.org.uk (accessed October 2011).

Design for All Foundation, 2003. Design for All Foundation. PDF available online at. www.designforall.org (accessed October 2011).

Eden, E., Enga, A., Lin, Y., Reimann, G., 2007. Design and gender: thinking about sex. In: Include 2007 Conference Proceedings, ISBN 1-905000-34-0.

Elkington, J., 1998. Cannibals with Forks: the Triple Bottom Line of 21st-century Business. New Society Publishers, ISBN 0865713928.

Elton, E., Nicolle, C., 2010. The Importance of Context in Inclusive Design. Ergonomics Society Annual Conference 2010-Keele University. Contemporary Ergonomics 2010.

Google, 2010. Ten Principles that Contribute to a Googley User Experience. www. google.com/corporate/ux.html (accessed October 2011).

Grundy, E., Ahlburg, D., Ali, M., Breeze, E., Sloggett, A., 1999. Research Report 94: Disability in Great Britain. Corporate Document Services, London, UK.

Hosking, I.M., Waller, S.D., Clarkson, P.J., 2010. It is normal to be different: applying inclusive design in industry. Interacting with Computers 22 (6), 496-501.

Immersion, 2011. 50+ Fact and Fiction. www.immersionactive.com/resources/50plus-facts-and-fiction/ (accessed October 2011).

ISO 9241-11, 1998. Ergonomic Requirements for Office Work with Visual Display Terminals - Part 11: Guidance on Usability. PDF avail. at: www.iso.org (accessed October 2011).

Klironomos, I., Antona, M., Basdekis, I., Stephanidis, C., 2005. Promoting Design for All and e-Accessibility in Europe. White Paper. PDF available at: www.edean.org (accessed October 2011).

Lange, K., Becerra, R., 2007. Teaching universal design in Colombia: the academic approach of two universities. In: Include 2007 Conference Proceedings, ISBN 1-905000-34-0. PDF available at: www.hhc.rca.ac.uk (accessed October 2011).

Malcolm, T., 1998. Ford Focus Press Pack. Public affairs, Ford Motor Company Ltd, Brentwood, Essex.

Microsoft, 2003. The Wide Range of Abilities and Its Impact on Computer Technology. Microsoft Corporation, USA. Research conducted by Forrester Research, Inc. www.microsoft.com.

Money factory, 2011. Meaningful Access Press Release (accessed October 2011). www.moneyfactory.gov/uscurrency/meaningfulaccess.html.

Mynott, C., Smith, J., Benson, J., Allen, D., Farish, M., 1994. Successful Product Development: Management Case Studies. Available from: M90s Publications, DTI, Admail 528, London SW1W 8YT

Nestlé, 2012. Nestlé Inclusive Design: Easy-open Packaging. Packaging International News. January 2012, Week 4. www.packaging-int.com/news/nestl-inclusivedesign-easy-open-packaging.html (accessed October 2012).

Newell, A., 2003. The future for ICT. In: Clarkson, P.J. (Ed.), Inclusive Design: Design for the Whole Population. Springer, London.

OCAD University, 2012. Inclusive Design Research Centre. website. idrc.ocad.ca (accessed October 2011)

Philips index, 2010. America's Health \& Well-being Report. Phillips Centre for Health and Well-being. PDF avail. at: www.newscenter.philips.com (accessed October 2011)

Preiser, W., Ostroff, E., 2001. Universal Design Handbook. McGraw Hill, New York, USA.

Pruitt, J., Adlin, T., 2006. The Persona Lifecycle: Keeping Users in Mind throughout the Design Process. Morgan-Kaufmann, San Francisco.

Rogers, M., 2009. Boomers and Technology: an Extended Conversation. AARP Press Release Avail. at: www.aarp.org (accessed October 2011).

United Nations, 2006. Convention on the Rights of Persons with Disabilities. Avail. at: www.un.org (accessed October 2011)

Waller, S.D., Langdon, P.M., Clarkson, P.J., 2010. Designing a more inclusive world. Journal of Integrated Care 18 (4), 19-25.

Warburton, N., Desbarats, G., Hosking, I., 2015. Developing inclusive design expertise within a client/consultancy relationship. Applied Ergonomics 46, 274-278.

Wright, E., 2010. 2008-based National Population Projections for the United Kingdom and Constituent Countries. Pdf avail. at: www.ons.gov.uk (accessed October 2011) 